\title{
Achievements of Junior Secondary School Students in Essay writing in French Using Activity based and Lecture Methods
}

\author{
Borode. Bolaji. R \\ Curriculum Studies Department, \\ Faculty of Education, Ekiti State University, Ado-Ekiti, Nigeria \\ E-mail: bolajiborode@gmail.com
}

Doi:10.5296/jsr.v5i2.6150

URL: http://dx.doi.org/10.5296/jsr.v5i2.6150

\begin{abstract}
The study sets out to examine the achievements Junior Secondary Schools students in essay writing in French using activity based and lecture methods. It adopts the quasi experimental research design. A French achieving test for junior secondary school III was used for data collection, it was analysed using mean, standard deviation and analysis of covariance. It eventually comes out with the view that activity based method of teaching essay writing is better for positive achievement in essay writing. Therefore government should train and retain French teachers on activity-based method of teaching essay writing.
\end{abstract}

Key Words: Achievement, essay writing, French language, lecture method, activity-based method.

\section{Introduction}

French language is one of the most widely used languages in the world. It ranks third after Chinese and English. Native speakers of French are found in every continent. Barriers of race colour and creed are no hindrance to continuing spread of the use of French language. It is one of the major languages of debate at the United Nations and a medium for commerce and education. A good knowledge and command of the language is a passport to social and economic advancement.

Meanwhile, the official language of the Nigerian educational system is English while French remains a foreign language in the country. In Nigeria, most of the students offering French Language have already acquired their mother tongue before joining the school system. Particularly the students in Ekiti State have already acquired Yoruba language before their admission into formal school system. At school, they are introduced to the second language (L2) which is English. By the time they are introduced to French Language in the Junior Secondary School, they are already in a complex situation. There is the interference of the previous two languages (native and English language).

At present, French language is one of the core subjects in the Junior Secondary School 
National Examination Council syllabus and its curriculum includes the development of all the (four) language skills (listening, speaking, reading and writing)

The major concern of this study is writing in French language in Nigeria. Writing like speaking is a productive language skill. It is a means of communication with people who may be far away. It is an externalisation and expression of what has been internalised. It is a visible communication medium by means of symbols marked or impressed on an equally physical material. It is the making of letters or other acceptable symbols. It involves marks and letters which may be recorded on any surface such as parchment, scroll, animal skins, paper, stone, tablet, clay or wood. Writing is therefore a way of representing on paper or other materials what is spoken, heard, read or taught about. This work shall be more concerned with achievement in writing as carried out in composition writing.

There are many factors that affect student's achievement in their academics, among which are anxiety, degree of preparation for examination, income of parents, method of teaching, techniques of studying and a host of others. The concept of academic performance of students has continued to receive attention in literature. The reason being that academic performance is the product of the teaching and learning process. Hence, the career and aspiration of students hand on the good or poor academic performance they manifest. It is obvious that the roles of parents in the successful performance of their wards cannot be over-emphasized. Many variables are related to achievement such as:

$>$ Parents socio-economic and education status

$>$ School administration

$>$ Effectiveness of the language teachers (availability and behaviour of teachers)

$>$ Teaching methods

$>$ Attitudes of students to language learning

$>$ Size of classes

$>$ Textbooks available

In order to measure performance, Kolawole (1998) highlights the following classification of tests:

$>$ The attainment/achievement test which ascertains how much is known, is on a set syllabus at a given point in the course

$>$ The proficiency test, which, like attainment/achievement test, ascertains what is known at a given point without reference to a specific syllabus through the test itself is standardized and validated for ranking purposes

$>$ The aptitude test, which predicts success/failure from the result of a given test. The major concern of this study is to measure performance of students in essay writing in French by the use of an achievement test. An achievement test is the test used so often and almost exclusively in public schools and in class examinations

Akinwamide (2009) affirms that the student's inability to write a comprehensive acceptable essay is due mainly to the method used in teaching. Methods are the ways educational aims are translated to practice as well as to reality. The methods used in teaching are not static but dynamic and thus change as the aims of language learning change. In addition, methods could be influenced by the quality of the teacher and the available 
instructional materials at his disposal. It is important for the teacher to have the adequate knowledge of different methods and their application in his day-to-day teaching.

Activity based method was one of the methods used in this study and it involves the use of activities in teaching such as identification, formation and usage of phrases and clauses formation and usage of sentences and paragraphs and regular writing of essays and specific correction of mistakes in marked essays. It also involves the use of dictionaries to build students' vocabulary, where necessary and performing other activities that will enhance good writing. Activity based method makes use of real-life situations that necessitate communication. It makes use of the constructivism learning theory, which promotes active learning where each learner is viewed as unique. It encourages each learner to arrive at his/her own version of the truth. Instructors play the role of facilitator. It is the generally accepted norm in the field of second or foreign language teaching. In this method, the teacher sets up a situation that students are likely to encounter in real-life. The activity based method can leave students in suspense as to the outcome of a class exercise, which will vary according to their reactions and responses.

The second method used for this study was the lecture method. It is the most commonly used method for transferring information in education. There are however, serious questions regarding the effectiveness of this traditional lecture method. Arredondo (1994) points out that, although lecture method is used extensively in education, many lecturers are not trained in giving lectures and according to Swanson and Torraco (1995) lecture was established formally centuries ago as a teaching process that began with a literal reading of important passages from the text. Students were expected to sit, listen, and take notes. In writing about lecture method education, Vella (1992) defines lecture as the formal presentation of content by the educator. (Subject matter expert) for the subsequent learning and recall in examinations by the students. Mclntosh (1996) observes that lecturing is frequently a one-way process unaccompanied by discussion, questioning, or immediate practice, which makes it a poor teaching method. Therefore, if right from secondary school level, the students do not have the opportunity of going through a well orchestrated method of developing how to write French language, the situation may be too bad in tertiary institution. Okedara and Odeh (2002) opined that over the years, the problem of poor writing skill has persisted and that this reveals that the convenient method of teaching writing is therefore ineffective. Hence, the different views and opinions on the nature of writing make investigation into ways of developing the writing skill inevitable and essential.

In French essay writing, it is of note that students may at the end of their school course have difficulty with the correct form of French verb and may be incapable of writing a single sentence correctly. This is common particularly among the Junior Secondary School Students. Therefore, the French language learners are expected to be exposed to rules governing the language to minimize the interference with the mother tongue. The teacher should as well identify areas of similarities to avoid over-generalization resulting in ungrammatical expression in French Language. For example, a student may want to write "J'ai douze ans" and may eventually write "je suis douze and". He can also write "Je suis faim" instead of "J'ai faim". Such deficiencies could do a lot to mar the composition of French language learners. Structural differences do not only exist, but they also have a 
negative transfer to the writing of French language by foreign students. Nunan (1999) says that, writer faces two main tasks. The first is generating ideas in language and the second is composing such ideas into written structures adapted to the needs of the reader and the goals of the writer. Other things which determines effectiveness in writing is the purpose of the discourse and the appropriateness of the register to the context or situation. Also the technical nature of writing and the need to use writing to express ones thought in a logical and coherent manner call for it to be taught well.

\section{STATEMENT OF THE PROBLEM}

Observation and experience by the researcher revealed that Secondary school teachers talk about essay or composition writing in French rather than engaging students in actual writing. On the part of students, it has also been observed that they are exited at the mention of French language lesson but they become cold and uninterested when it comes to essay writing. It seems the method of teaching could be responsible for this.

\section{PURPOSE OF THE STUDY}

The purpose of this study is to find the effect of activity based, and lecture methods on the achievement of Junior Secondary School French students in essay writing

\section{RESEARCH QUESTION}

Question 1: What are the achievements of students in activity based, lecture method and the control groups in pre test?

Question 2: what are the achievements of students in activity based lecture method and control group in post test?

\section{METHODOLOGY}

This study was a three group; Pre-test, post-test, quasi- experimental design. The population of the study was 2319 Junior Secondary School students in Ekiti State. A sample of 120 Junior Secondary school III students were selected from six mixed secondary schools based on multi-stage stratified and purposive random sampling techniques

The instrument used for data collection was French Achievement test for junior Secondary School III (FATFJSS). The researcher first administered a pre-test to all the subjects after which research assistants were used to teach with the two methods for six weeks, a post-test was conducted and scored in all the groups. Data was analysed using mean, standard deviation and analysis of co-variance.

Results: What are the achievements of students in activity based, lecture method and the control groups in pre-test 


\section{MInstitute Macrothink $_{\text {Int }}$}

Table 1: means, standard deviation and variance of students' achievement in essay writing in pre-test.

\begin{tabular}{|l|l|l|r|c|}
\hline Method & N & \multicolumn{3}{|c|}{ Pre test } \\
\hline & & $\begin{array}{l}\text { Mean } \\
\text { Variance }\end{array}$ & & SD \\
\hline Activity based & 40 & 25.81 & 13.23 & 175.03 \\
\hline Lecture & 40 & 22.50 & 11.32 & 128.14 \\
\hline Control & 40 & 16.75 & 8.27 & 68.3 \\
\hline
\end{tabular}

Table 1 shows that the pre test mean scores of students' achievement in activity-based, lecture method and control groups were 25.81, 22.50 and 16.67 respectively. This shows that there is just a slight difference between the standard deviation of activity based and lecture method.

Question 2: what are the achievements of students in activity based, lecture method and the control group in post test?

Table 2: Means, Standard Deviation And Variance Of Students' Achievement In Essay Writing In Post-Test.

\begin{tabular}{|l|l|l|r|r|}
\hline Method & N & \multicolumn{3}{|c|}{ Post test } \\
\hline & & $\begin{array}{l}\text { Mean } \\
\text { Variance }\end{array}$ & & SD \\
\hline Activity based & 40 & 38.81 & 14.80 & 219.04 \\
\hline Lecture & 40 & 28.56 & 14.23 & 203.49 \\
\hline Control & 40 & 16.31 & 7.49 & 56.10 \\
\hline
\end{tabular}

Table 2 shows that the post test means scores of students' achievement in activity based, lecture method and control group were 38.81, 28.56 and 16.31 respectively. The standard deviation of both activity-based and lecture method shows that activity based method of teaching had a higher positive effect on the achievement of students in essay writing in French, while lecture method was not as high as Activity based.

\section{CONCLUSION}

From the above findings, activity based method was found pedagogically rewarding and reliable in the teaching of essay writing. It is rewarding because students are able to contribute actively in class, they are able to benefit from the contributions of others. They are able to generate ideas and also are able to go into actual writing as often as possible. Based 
on these findings, French teachers should make use of activity based method of teaching essay writing as it has higher positive effect on the achievement of students than lecture method. Above all, French teachers should be given adequate orientation through workshops, seminars and in-service training to update the knowledge on activity-based method of teaching essay writing

\section{REFERENCES}

Akinwamide T.K (2009) Effects of Process-Approach on Students' Creativity in Essay writing. Ph.D Thesis, Unpublished. Akungba: Adekunle Ajasin University.

Arredondo M.A (1994) “The use of videotaped lectures" in Oncology Journal of Cancer Education. 9(2)

Kim (2005): The effects of a Constructivist teaching Approach on Student Academic Achievement, Self Concept and Learning Strategies: Asia Pacific Education-Review.

Kolawole C.O (1998) Linguistic inputs and Three Methods of Presentation as Determinanats of students' Achievement in Senior Secondary Scool Essay-Writing in Ibadan. Unpublished Ph.D Thesis, University of Ibadan.

Mclntosh N. (1996): 'Why Do We Lecture?' JHPIEGO Strategy Paper \#2. JHPIEGO Corporation. Baltimore, Maryland.

Nunan (1999): Second Language Teaching and learning. HEINE\&HEINE.

Odejide B.I. (1980) The Use of Models in the Teaching of Composition. West African Journal of Education in Nigeria

Okedara C.A. and Odeh S. (2002): Trends in the Teaching of Composition at the Tertiary Level. The Process Writing Approach: Stirling-Horden Pub. Ltd.

Swanson R.A and Torraco R.J (1995) The History of Technical Training in the AS TD Technical Skills Training Handbook. Kelly L. (ed) M.C Graw Hill: New York

Vygotsky (1998): Thought and Language. The MIT Press, Cambridge.

Wella F (1992): Medical Education, Capitalization on the Lecture method FASEB Journal 6(3), 811-812.

Zwick, R. (2002). Fair game? The use of standardized admissions test in higher education. New York: Routledge Falmer. 